Original article

\title{
Screening for vision impairment and ocular morbidities among adolescents and young adults in urban and rural areas of southern part of India
}

\author{
Aparna Mohandas, Smitha Malenahalli Chandrashekarappa*, Jenee Dowerah, Praveen Kulkarni, \\ D. Sunil Kumar, M.R. Narayana Murthy, Nayanabai Shabadi, M. Shwethashree
}

Department of Community Medicine, JSS Medical College, JSS Academy of Higher Education and Research, Mysuru, Karnataka, India

\section{A R T I C L E I N F O}

\section{Keywords:}

Vision impairment

Snellen's chart

Screening

\begin{abstract}
A B S T R A C T
Introduction: Globally 1.3 billion people suffer from vision impairment, $80 \%$ of which are due to avoidable causes. The prevalence of childhood blindness in developing countries is 1.5 per $1000.30 \%$ of blind people in India lose eyesight before the age of 20 , hence early diagnosis and correction becomes imperative

Objectives: To determine the burden of vision impairment using Snellen's chart and other ocular morbidities among adolescents and young adults in urban and rural areas of Southern part of India. 2. To determine the association of age, gender and place of residence with vision impairment among them.

Methodology: This cross-sectional study was conducted as part of annual health check-up in 50 schools, colleges in southern part of India, during 2018-2019.11085 students between 10 and 25 years were screened for visual acuity using Snellen's chart and ocular morbidities. Data was entered in Excel and analysed using SPSS Version 23. Descriptive statistics like mean, standard deviation, percentages and inferential statistical tests like chi square test was used.

Results: $4.2 \%$ had vision impairment $(<6 / 12) .5 .2 \%$ and $3.2 \%$ students residing in urban and rural areas and $4.1 \%$ of adolescents and $5.6 \%$ of young adults had vision impairment. Gender, place of residence and age groups were significantly associated with visual impairment. Prevalence of various ocular morbidities were bacterial conjunctivitis $(0.13 \%)$, squint $(0.13 \%)$, stye $(0.1 \%)$, conjunctival xerosis $(0.1 \%)$ and allergic conjunctivitis (0.05\%)

Conclusion: Significant proportion of the adolescents and young adults had vision impairment. Periodic screening and correction would be effective solution
\end{abstract}

\section{Introduction}

Globally 1.3 billion people suffer from vision impairment of which 36 million people are blind. ${ }^{1} 89 \%$ of the visually impaired people live in low and middle income countries. ${ }^{2}$ The prevalence of childhood blindness is about $0.3 / 1000$ in developed countries and as high as 1.5/ 1000 in developing countries. ${ }^{3} 12$ million children in the age group of 5-15 years suffer from vision impairment due to uncorrected refractive errors and studies have shown that more than $90 \%$ of vision impairment is caused by myopia. ${ }^{4}$

World Health Organization (WHO) states that $80 \%$ of vision impairment is due to avoidable causes, hence they developed the global action plan 2014-2019 with an aim to reduce vision impairment due to avoidable causes by $25 \%$ by the year 2019 and to ensure rehabilitative services, to develop cost effective intervention in eye care and to promote innovations in preventing and treating eye disease through coordinated actions by the member states. The major objective of VISION 2020-The Right to Sight, a global initiative taken up by WHO and International Association of Prevention of Blindness (IAPB) is to eliminate avoidable blindness and vision impairment due to uncorrected refractive errors. ${ }^{1,5}$

In India $1.1 \%$ of the population are blind. In school going children, the prevalence of refractive errors is $2-3 \%$ and $5.5 \%$ in rural and urban areas respectively. ${ }^{4}$ Studies show that $30 \%$ of India's blind population lose their vision before they turn 20 years. ${ }^{6}$

Uncorrected refractive errors are the leading cause of vision impairment in the world followed by cataract, age related macular degeneration, glaucoma, diabetic retinopathy, corneal opacity and trachoma. With an increasing population and an increase in older generation there is an even more risk of vision impairment. ${ }^{1}$ In India the leading cause of blindness is cataract followed by refractive errors which accounts for $19.7 \%$ of all the causes. ${ }^{7}$ The major cause of

\footnotetext{
* Corresponding author. Department of Community Medicine, JSS Medical College, Mysuru, 570017, Karnataka, India.

E-mail address: smithamc@jssuni.edu.in (S.M. Chandrashekarappa).
} 
childhood blindness in our country is refractive errors followed by Vitamin A deficiency, congenital abnormalities and retinoblastoma. ${ }^{3}$ Long duration of exposure to smartphones, computers and television have further added to this burden.

The student period is the formative period in one's life, both physically and mentally and helps transform one into a productive individual. Students are affected by various ocular morbidities like refractive errors, vitamin A deficiency, squint and eye infections. ${ }^{6}$ Poor vision can have a deleterious effect on the academic performance. Visual acuity is given immense importance in certain fields like military, navy and aviation, hence timely detection and correction can help students choose a career of their choice. Most children may not be able to complain of defective vision hampering the early detection and timely correction. ${ }^{7}$ In India the school eye screening program was started under the National program for prevention and control of blindness in the year 1994 where school teachers play a major role by acting as primary screeners. ${ }^{9}$ Vision impairment is a social issue as it can cause loss of educational, employment and economic opportunities, however it is avoidable. With this background the aim of this study was to determine the proportion of adolescents and young adults having impaired vision and to determine the prevalence of other ocular morbidities among them.

\section{Objectives}

1. To determine the burden of vision impairment using Snellen's chart and other ocular morbidities among adolescents and young adults in urban and rural areas of Southern part of India.

2. To determine the association of age, gender and place of residence with vision impairment among them.

\section{Materials and methods}

This cross-sectional study was conducted as part of the annual health check-up among adolescents and young adults in urban and rural areas of Mysuru, Chamarajanagar and Mandya districts, Karnataka, India during the year 2018-2019 for the duration of one year. All the schools and colleges under JSS institutions of Mysuru, Chamarajanagar and Mandya districts were included for the annual health check-up. Students with wide diversity with respect to socio-demographic profile are admitted in these institutions. Out of the 52 schools and colleges, students of two schools were not screened due to unavoidable circumstances and all the adolescents and young adults in the remaining 50 schools were screened for visual impairment and ocular morbidities. A total of 11085 students were screened. The selection process is elaborated in Fig. 1. Consent was taken from the head of the institution and students above 18 years and assent was taken from students between 12 and 18 years along with the consent from their parents and oral consent was obtained from adolescents between 10 and 12 years with consent from their parents according to recent ICMR guidelines and General information like the name, age, sex and class were obtained. Screening for visual acuity was done using Snellen's chart, the sensitivity and specificity of which in detecting visual acuity are $89 \%$ and $62 \%$ respectively. ${ }^{10}$ Students between 10 and 25 years were selected assuming that they would be more compliant to the screening procedure adopted. The chart was fixed on a wall in a well-lit room and the student was made to stand at a distance of $6 \mathrm{~m}$ and read the Snellen's chart with each eye separately by closing the other eye using the palm. They were also instructed not to apply undue pressure on the other eye as it would affect vision while reading the chart. The readings were recorded. Impaired visual acuity was defined with the visual acuity less than 6/12. During the same sitting, adolescents and young adults were also screened for ocular morbidities by trained medical graduates by clinical examination. Institutional ethical committee clearance was obtained before the start of the study.

\subsection{Statistical analysis}

The data obtained was entered in Microsoft Excel spreadsheet and analysis was done using SPSS Version 23 (licensed to JSS Academy of Higher Education and Research). Descriptive statistical methods like mean, standard deviation and percentages and inferential statistical tests like the chi - square test was used. Data was presented using pie charts, bar charts and tables accordingly.

\section{Results}

Out of the 11085 students screened for visual acuity, 4961(44.8\%) were males and 6124(55.2\%) were females as shown in Fig. 2. The mean age of students was $15.2 \pm 2.6$ years. Of the 11085 students, $4632(41.8 \%)$ were residing in urban areas and 6453(58.2\%) were residing in rural areas. Among the 11085 students, 9975(90\%) belonged to the age group of $10-19$ years and $1110(10 \%)$ belonged to $20-25$ years age group. In our study among 11085 students, we found that $10617(95.8 \%)$ students had normal vision and 468(4.2\%) students had vision impairment $(<6 / 12)$. Fig. 3 represents the distribution of students with vision impairment based on gender. According to the ICD-11 classification of diseases, vision impairment is classified as mild, moderate, severe visual impairment and blindness. Among 11085 study participants $1.6 \%$ had mild vision impairment, $2.53 \%$ had moderate to severe vision impairment and $0.02 \%$ had blindness as shown in Table 1. Among the 6124 females, 281(4.6\%) had impaired vision while only $187(3.8 \%)$ of the 4961 males were affected. There was a significant association between gender and vision impairment ( $p<0.03$ ). $5.7 \%$ of the students residing in urban area and $3.2 \%$ students residing in the rural areas had impaired vision as shown in Table 2. Place of residence was found to be significantly associated with vision impairment ( $\mathrm{p}<0.001$ ). Table 3 represents the distribution of study participants based on age. $4.1 \%$ of the adolescents and $5.6 \%$ of the young adults had impaired vision. There was a significant association between age groups and vision impairment $(\mathrm{p}<0.02)$. Table 4 shows the distribution of students based on ocular morbidities. Among 11085 students 14(0.13\%) had bacterial conjunctivitis, $5(0.05 \%)$ had allergic conjunctivitis and $7(0.1 \%)$ had stye. These cases were treated accordingly. $7(0.1 \%)$ students who had conjunctival xerosis were referred to higher centres for further evaluation and management. 15 students $(0.13 \%)$ had squint.

\section{Discussion}

In the present study conducted among 11085 students in the age group of 10-25 years, it was found that $4.2 \%$ of the students had impaired vision $(<6 / 12)$. In a similar study conducted by John et al. among 6th to 9th standard students in rural Tamil Nadu, $2.3 \%$ failed the screening test, which was less compared to the present study. ${ }^{9}$ This was probably because of the wider age group covered in this study. Aroor et al. in Surathkal reported that $18.5 \%$ had visual defects and Samant et al. reported $21.80 \%$ had defective vision in rural Maharashtra. ${ }^{3,11}$ The higher prevalence in the above studies can be attributed to the difference in criteria and cut offs taken by different authors to define impaired vision.

According to the ICD-11 classification, blindness is defined as presenting distance visual acuity worse than $3 / 60^{1}$. In India, under the National Program for Control of Blindness and Vision Impairment, the definition of blindness has been modified as presenting visual acuity of less than $3 / 60$ in the better eye. ${ }^{12}$ In this study $1.6 \%$ had mild vision impairment and $2.53 \%$ had moderate to severe vision impairment. The prevalence of blindness was $0.02 \%$ which is almost similar to the findings of Singh et al. who reported a prevalence of $0.06 \%$ in Uttar Pradesh. ${ }^{13}$ Dandona et al. reported a prevalence of $0.15 \%$ which was slightly higher than our findings which can be explained by the use of older cut off $(<6 / 60)$ of blindness in India. ${ }^{14}$ 


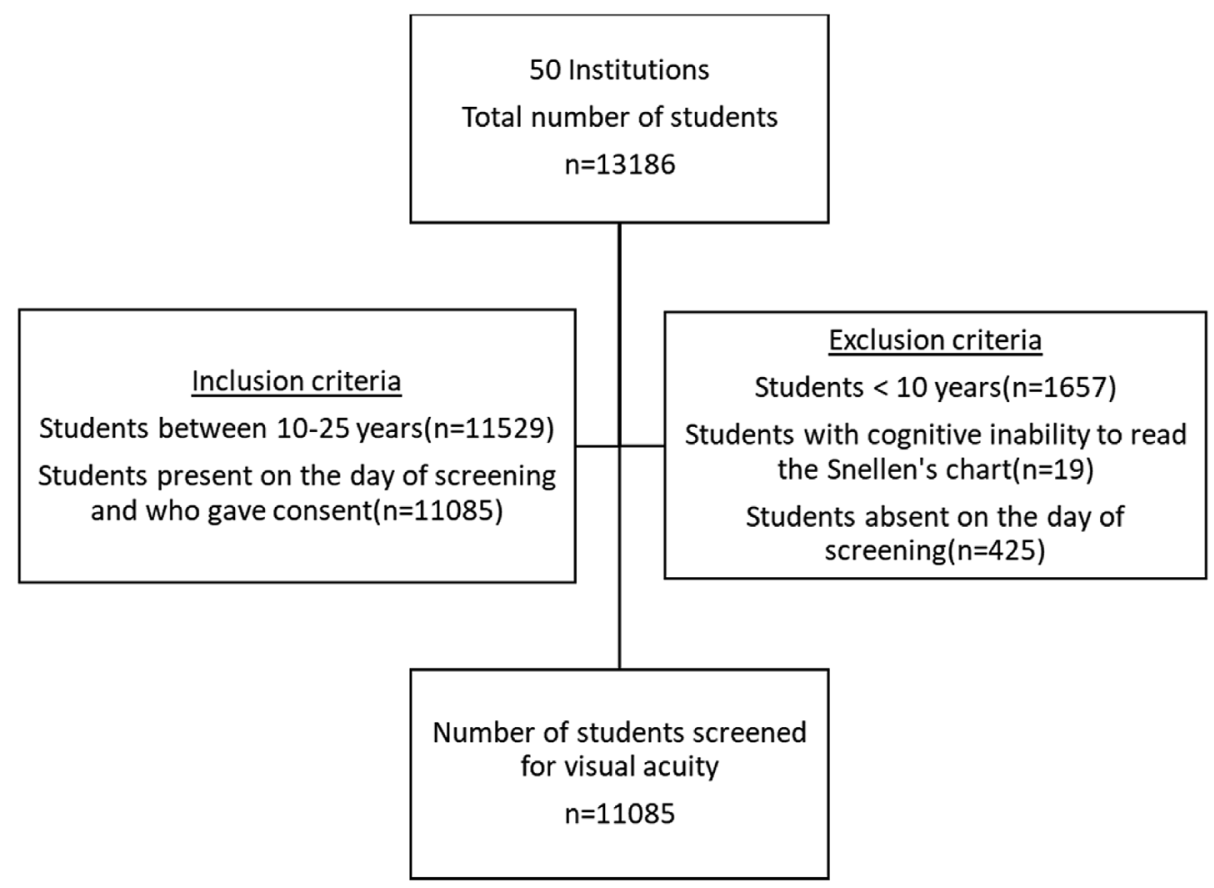

Fig. 1. Selection process of students for screening for visual acuity.

Distribution of students based on Gender $(\%) ; \mathbf{n}=\mathbf{1 1 0 8 5}$

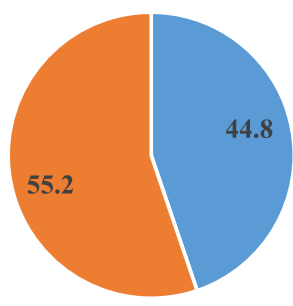

- Males - Females

Table 1

Distribution of students based on ICD-11 classification of vision impairment.

\begin{tabular}{lllll}
\hline Category & \multicolumn{4}{l}{ Presenting visual acuity } \\
\cline { 2 - 5 } & Worse than & $\begin{array}{l}\text { Equal to or better } \\
\text { than }\end{array}$ & $\mathrm{n}$ & $\%$ \\
& & $6 / 12$ & 10617 & $95.8 \%$ \\
\hline $\begin{array}{l}\text { Normal vision } \\
\text { Mild vision impairment }\end{array}$ & $6 / 12$ & $6 / 18$ & 182 & $1.6 \%$ \\
$\begin{array}{l}\text { Moderate vision } \\
\quad \text { impairment }\end{array}$ & $6 / 18$ & $6 / 60$ & 281 & $2.5 \%$ \\
$\begin{array}{l}\text { Severe vision impairment } \\
\text { Blindness }\end{array}$ & $6 / 60$ & $3 / 60$ & 3 & $0.03 \%$ \\
Total & $3 / 60$ & $1 / 60$ & 2 & $0.02 \%$ \\
& & & 11085 & $100 \%$
\end{tabular}

Table 2

Distribution of students with vision impairment based on place of residence.

\begin{tabular}{llll}
\hline & Normal & Impaired vision & Total \\
\hline \multirow{2}{*}{ Urban } & 4368 & 264 & 4632 \\
& $94.3 \%$ & $5.7 \%$ & $100 \%$ \\
\multirow{3}{*}{ Rural } & 6249 & 204 & 6453 \\
& $96.8 \%$ & $3.2 \%$ & $100 \%$ \\
\hline
\end{tabular}

In the present study $4.6 \%$ of the females and $3.8 \%$ males had impaired vision. Gender was found to be significantly associated with vision impairment with females being affected more as compared to males. This can be attributed to the fact that females attain puberty at an earlier age compared to males. ${ }^{15}$ Studies show that nutritional deficiency can lead to decreased visual acuity and a study from south

Distribution of students with vision impairment based on gender(\%); $\mathbf{n = 1 1 0 8 5}$

$60.00 \%$
$50.00 \%$
$40.00 \%$
$30.00 \%$
$20.00 \%$
$10.00 \%$
$0.00 \%$

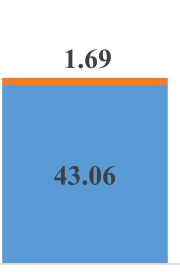

Males

- Normal vision $\quad$ Vision impairment
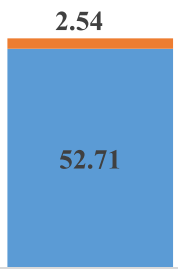

Females

Fig. 3. Distribution of students with vision impairment based on gender (\%); $\mathrm{n}=11085$. 
Table 3

Distribution of students with vision impairment based on age.

\begin{tabular}{llll}
\hline Age groups & Normal & Impaired vision & Total \\
\hline \multirow{2}{*}{$10-1$ yyears } & 9569 & 406 & 9975 \\
& $95.9 \%$ & $4.1 \%$ & $100 \%$ \\
$20-25$ years & 1048 & 62 & 1110 \\
& $94.4 \%$ & $5.6 \%$ & $100 \%$ \\
\hline
\end{tabular}

Table 4

Distribution of students based on ocular morbidities; $\mathrm{n}=11085$.

\begin{tabular}{lll}
\hline Ocular morbidities & Number & $\%$ \\
\hline Bacterial conjunctivitis & 14 & $0.13 \%$ \\
Allergic conjunctivitis & 5 & $0.05 \%$ \\
Stye & 7 & $0.1 \%$ \\
Conjunctival xerosis & 7 & $0.1 \%$ \\
Squint & 15 & $0.13 \%$ \\
\hline
\end{tabular}

India reported that malnourishment is more prevalent in females compared to males, which could be another reason for the difference in visual acuity among males and females that we noted in our study. ${ }^{16,17}$ This was similar to the findings of John et al. where the proportion of affected females $(2.75 \%)$ was more compared to the males $(1.97 \%)$ and Saha et al. where $17.3 \%$ of the females and $10.9 \%$ males had impaired vision. ${ }^{9,18}$ Shakeel et al. reported a slightly higher prevalence among males (13.5\%) than females (12.4\%) in Dehradun, however it was not statistically significant. ${ }^{15}$

It was found that $5.7 \%$ and $3.2 \%$ of students residing in urban and rural areas were affected. More students were affected in the urban areas and place of residence was found to have a significant association with vision impairment. This was similar to the findings of Uzma et al. in rural and urban school children in Hyderabad, where the prevalence of uncorrected impaired vision in urban and rural schools were $9.8 \%$ and $6.6 \%$ respectively and the study by Singh et al. where $0.62 \%$ in urban area and $0.37 \%$ in rural area were affected. ${ }^{13,19}$ In all these studies urban students were affected more and this probably can be attributed to the higher exposure to smartphones and computer screens for longer duration among the urban students. ${ }^{3}$

In the present study $4.1 \%$ of the adolescents (10-19 years) had impaired vision. In hospital-based studies, Rohul et al. reported a prevalence of $54.62 \%$ for refractive errors in $12-18$ years age group in Kashmir and Malhotra et al. reported a prevalence of $52.22 \%$ among adolescents in Uttar Pradesh. ${ }^{7,8}$ The higher prevalence might be due to the difference in the study setting. In a field-based study by Dandona et al. in rural Hyderabad among children of 7-15 years age group, $2.7 \%$ were found to have a visual acuity less than or equal to 20/ 40 (equivalent to $6 / 12$ in Snellen's chart) which was less compared to the present study probably because of the lower age group selected. ${ }^{14}$ Among the young adults (20-25 years), it was found that $5.6 \%$ were affected. There is a paucity of literature on the prevalence of vision impairment in this age group. Chelliah et al. in her study among medical students (17-25 years) in south India found that the prevalence of refractive errors was $69.4 \%$, which was much higher than the present study probably because of the wider age group. ${ }^{20}$

In the present study it was found that the prevalence of bacterial conjunctivitis was $0.13 \%$, which was less compared to a prevalence of $2.3 \%$ in the study by Kamath et al. among children in rural Karnataka in 2012 and $0.95 \%$ in a study by Singh et al. in Western Uttar Pradesh between 2012 and 2014, which is probably because of the better hygiene, the advocacy of handwashing practices among children and an indicator for reduced infections over the years. ${ }^{6,13}$ The prevalence of allergic conjunctivitis in this study was $0.05 \%$ which less compared to a prevalence of $1.92 \%$ in the study by Singh et al. in western Uttar Pradesh which can be attributed to the difference in region and weather conditions. ${ }^{13}$

Vitamin A deficiency in the form of conjunctival xerosis was seen in $0.1 \%$ of the study population which was much less compared to the prevalence of $4.6 \%$ in a study conducted by Mahesh et al. in tribal children in Tamil Nadu and Kamath et al. who reported a higher prevalence of $33.8 \%$ in rural Karnataka. ${ }^{6,21}$ This difference might be due to the difference in socioeconomic status and nutritional profile. ${ }^{21}$

\subsection{Strength}

The study included a huge sample size encompassing the entire adolescent period including early, middle and late adolescence, also including the young adults who hailed from both urban as well as rural background. Additionally, the present research with the finding of around $5 \%$ of vision impairment on screening, highlights the importance of periodic screening of vision and early intervention among school children.

\subsection{Limitation}

Snellen's Chart used as the screening tool in the present study could not assess the near vision. Further some researchers suggest that, Snellen's chart due to the variation in the number of letters present in each subsequent line, leads to "visual crowding" at the higher visual acuity level making it less reliable. ${ }^{22}$

\section{Conclusion}

In this study we found that a significant proportion of adolescents and young adults had impaired vision. Gender, age and place of residence were significant factors associated with vision impairment.

\section{Recommendations and scope for future research}

Vision impairment is an avoidable burden, hence continuation of periodic screening for early detection and ensuring that it is corrected is the best possible intervention.

Further research can be done to determine the association between screen time, vitamin A prophylaxis and diet with vision impairment and also vision impairment and its impact on scholastic performance needs to be explored.

\section{Declaration of competing interest}

None.

\section{References}

1. World Health Organization (WHO). Vision Impairment and Blindness Factsheet 2018. Geneva: WHO; 2018. [cited 2019 Aug 21]. Available from: https://www.who.int/ news-room/fact-sheets/detail/blindness-and-visual-impairment.

2. The International Agency for the prevention of Blindness (IAPB). Global Vision Impairment Facts 2019. [Internet]. United Kingdom: IAPB; 2019. cited 2019 Aug 21]. Available from:. https://www.iapb.org/vision-2020/who-facts/.

3. Samant PL, Bangal SV, Giri PA, Bhandari AJ. Refractive errors as a cause of childhood blindness in school going children of a rural set-up. International J. of Healthcare and Biomedical Research. 2015 Apr;3(3):45-51.

4. Vision 2020: Right to Sight- India. Vision Screening in School Children 2014[Internet]. Haryana: Vision 2020: Right to Sight- India; 2014. [cited 2019 Aug 5]. Available from: http://www.vision2020india.org/wp-content/uploads/2016/09/visionscreening-in-school-children-manual-1.pdf.

5. The International Agency for the prevention of Blindness (IAPB). VISION 2020: The Right to Sight 2019. [Internet]. United Kingdom: IAPB; 2019. [cited 2019 Aug 5]. Available from:. https://www.iapb.org/vision-2020/.

6. Kamath BP, Prasad BG, Deepthi R, Muninrayana C. Prevalence of ocular morbidity among school going children (6-15years) in rural area of Karnataka, South India. Int $J$ Pharm Biomed Res. 2012;3(4):209-212.

7. Rohul J, Magbool A, Hussain SA, Shamila H, Anjum F, Hamdani ZA. Prevalence of refractive errors in adolescents in out-patient attendees of the preventive ophthalmology clinic of community medicine, SKIMS, Kashmir, India. Nitte Univ J Health Sci. 2013 Mar 1;3(1):17. 
8. Malhotra AK, Tiwari N, Sirohi N. A cross sectional study on refractive errors among adolescents visiting medical college, Jhansi, UttarPradesh. IOSR J Dent Med Sci. 2016 May;13(5):26-29.

9. John DD, Paul P, Kujur ES, David S, Jasper S, Muliyil J. Prevalence of refractive errors and number needed to screen among rural high school children in southern India: a cross-sectional study. J Clin Res. 2017 Aug;11(8):NC16-NC19.

10. Rivakani F, Torabi L, Rafiei M, et al. The sensitivity, specificity and predictive values of snellen chart compared to the diagnostic test in amblyopia screening program in Iran. Int J Pediatr. 2015 Dec;3(6.2):1125-1133.

11. Aroor AR, Airody SK, Mahale R, Ravikiran SR, Shetty S, Rao AR. Anthropometry and prevalence of common health problems among school going children in Surathkal, Karnataka. J Clin Diagn Res. 2014 Dec;8(12):PC01-PC05.

12. Ministry of Health \& Family Welfare, Government of India. National Programme for Control of Blindness and Visual Impairment (NPCBVI) [Internet]. MOHFW. [cited 2019 Aug 13]. Available from: http://npcb.nic.in/index2.asp?slid =104\&sublinkid = 618langid $=1$.

13. Singh V, Malik PS, Malik V, Jain K. Prevalence of ocular morbidity in school going children in West Uttar Pradesh. Indian J Ophthalmol. 2017 Jun 1;65(6):500-508.

14. Dandona R, Dandona L, Srinivas M, et al. Refractive error in children in a rura population in India. Invest Ophthalmol Vis Sci. 2002 Mar 1;43(3):615-622.

15. Shakeel T, Mittal SK. Pattern of refractive errors in primary school children in
Dehradun city of uttrakhand state. Delhi J Ophthalmol. 2016 Dec 1;27(2):106-110.

16. Thomas B, Umapathy E, Iputo J. Effects of nutritional deficiency on visual acuity. $J$ Biol Sci. 2008;8(7):1246-1250.

17. Joseph B, Rebello A, Kullu P, Raj VD. Prevalence of malnutrition in rural Karnataka, south India: a comparison of anthropometric indicators. J Health Popul Nutr. 2002 Sep;20(3):239-244.

18. Saha M, Chowdhury D, Ranjan A, Islam MN, Mukherji S. Prevalence of refractive errors among the school going children at a tertiary center of West Bengal. Int $J$ Sci Stud. 2017;5(4):179-182

19. Uzma N, Kumar BS, Khaja Mohinuddin Salar BM, Zafar MA, Reddy VD. A comparative clinical survey of the prevalence of refractive errors and eye diseases in urban and rural school children. Can J Ophthalmol. 2009 Jun;44(3):328-333.

20. Chelliah R, Mahalingam K, Ganesh V, Rangasamy R, Pattabiraman S, Narayanan N. Prevalence of refractive error among college students in south India: a pilot study. $J$ Med Sci Clin Res. 2018;6(12):547-552.

21. Mahesh KM, John D, Rose A, Paul P. Prevalence of ocular morbidity among triba children in Jawadhi hills, southern India: a cross-sectional study. Indian J Ophthalmol. 2019 March;67(3):386-390.

22. Lim LA, Frost NA, Powell RJ, Hewson P. Comparison of the ETDRS logMAR, 'compact reduced logMar'and Snellen charts in routine clinical practice. Eye. 2010;24(4):673-677. 